\title{
Impact of Logistics Management on Customer Satisfaction: A Case of Retail Stores of Islamabad and Rawalpindi
}

\author{
Anwar Syed Umair, Wuyi Zhang, Zhengtao Han, Syed Hammad Ul Haq \\ Faculty of Economics \& Management, Kunming University of Science \& Technology, Kunming, China \\ Email: syeddumair@hotmail.com
}

How to cite this paper: Umair, A.S., Zhang, W.Y., Han, Z.T. and Ul Haq, S.H. (2019) Impact of Logistics Management on Customer Satisfaction: A Case of Retail Stores of Islamabad and Rawalpindi. American Journal of Industrial and Business Management, 9, 1723-1752.

https://doi.org/10.4236/ajibm.2019.98113

Received: July 4, 2019

Accepted: August 26, 2019

Published: August 29, 2019

Copyright $\odot 2019$ by author(s) and Scientific Research Publishing Inc. This work is licensed under the Creative Commons Attribution International License (CC BY 4.0).

http://creativecommons.org/licenses/by/4.0/

(c) (i) Open Access

\begin{abstract}
The main purpose of this study was to analyze the impact of logistics on the customer satisfaction of the retail stores, in the twin cities of the Islamabad and Rawalpindi. The factors of logistics in the study were inventory, lead time, transportation and logistics. A survey questionnaire divided into two parts was adopted, one part for the factors of logistics and the other one for customer satisfaction for the measurement of variables in the research. Where the introductory portion deals with the demographic items and then the first part contain items tend to identify the score for each factor of logistics and then second part is for the customer satisfaction. In the study through convenient sample technique 200 stores of the twin cities of Islamabad and Rawalpindi are chosen for research. The findings of the research demonstrate that factors of logistics which are inventory, lead time, transportation and logistics doe's effect customer satisfaction. Moreover, logistics has shown positive relationship with customer satisfaction of the retail stores. In conclusion, results have shown significant interaction of customer satisfaction with inventory, lead time, transportation and logistics. The study covers only the geography of Islamabad and Rawalpindi in the present research therefore; to have more better and generalizable insights future studies must include investors from other parts of the country. However, large sample size can also be used in the future studies. Practices like multiple effective transportation system, which reduces the lead time and maintaining the inventory in the stores and to make sure the availability of the products required by the customer is important for the customer satisfaction. Till date, few studies are done in this context, so this study will help in the academics and the customer satisfaction in the retail.
\end{abstract}

\section{Keywords}

Supply Chain, Supply Chain Management, Inventory, Lead Time, 
Transportation and Logistic

\section{Introduction}

As the business environment is uncertain nowadays, and it is very hard to be constant at success, so the business must respond to the uncertainty and meet the customer needs as they are changing day by day Gerwin, 1987; Huber, 1984; Narasimhan and Das, 1999; Ward et al., 1998 [1]. As studied by Day 1994, the customer's awareness is increasing day by day and due to this they always need special treatment in design, how the products will be produced and delivered to them, and all this involves supply chain and within this supply chain, flexibility is one of the major factor to consider, so flexible supply chain perspective is more important than an equipment or the process perspective. The competition nowadays is increasing day by day, companies need to look for such processes and methods to manage the firm so that the firm will be enable to come up with efficiency and with much better outcomes Stock et al., 2000; Bañón and Sanchez, 2002 and Norek et al., 2007 [2]. As a study conducted by Bowersox et al. (2002) and Gunaseakaran and Ngail 2003 [3] logistics is such an important factor in any firm, which plays a key role in the differentiation in the market. As the present business environment is more intense competition wise, the pressure is not only on the differentiation in the product and service but also on the factors which reduces the price as well. According to Gil-Saura et al. 2010 [4], When it comes to the success and growth of a retail store or any business relating to the retail sector, then the role of logistics is very important as it plays a very important role. The performance of logistics is not only taken as the activity relating to operation but in fact it is taken as a strategic variable and it plays a key role in the satisfaction of the consumer. Customer always expects something and when they are not met then, the consumer will eventually be dissatisfied and the effect goes on by multiplying itself, and when this effect increases the consumer will switch to another retail competitor, and the former experience of dissatisfaction is abandoned by the consumer Bouzaabia et al., 2013 [5]. As Jennet 2011 stated that customers are one of the stakeholders of the organization and they are one of the most important, as looking at their importance it is one of the main goal of the Organization to satisfy the customer and their satisfaction is among the top of the list items for the management and this area which is customer satisfaction is in light by the organizations very much due to its importance [6]. Previous research suggested that the quality of services is a reason for customer satisfaction. Customers always expect something from the organization and if those expectations are met then they will be satisfied and it is proved that the behavior of customer is the foundation of the level of satisfaction for them, stated by Walidin and Waskita 2007 [7]. In Pakistan there has been research done on the logistics and the company performance and also environmental effects which included different aspects of logistics including the costs, warehous- 
ing and outsourcing the logistics operations and their effect on the company performance and the result which was concluded from the research that although sustainable logistics operations are difficult to obtain but if they are properly implemented including the environmental effect as well then the company and the country can be sustainable in different ways like economic social and environmental Abbasi Noman Muhammad et al., 2013 [8]. According to the report third quarter of 2017, by state bank of Pakistan, there is growth shown of about 1.2 percent from last year, and the report says that this growth will continue in the upcoming time. The increase in retail sector of Pakistan is due to the increased income, urbanization and customer awareness, which gives a hint towards the expansion of the retail market in Pakistan. According to the report, it's not the thing that Pakistan's retail sector is transforming from small retailers to large retailers, but also giant stores like next, Metro, Makro are in the country now, and giants like Marks \& Spencer, are also showing an interest to operate in the country. From all this is evident that the twin cities of the country are also expanding its retail sector, the figures of the last decade regarding the GDP 17.5 steady, and then and it also is the second largest employing, which is almost is $16 \%$. And currently around 2500 departmental stores in the twin cities of Islamabad and Rawalpindi. By looking at all the aspects, it is quite evident that the logistics plays a very vital role in the customer satisfaction, especially in retail sector. As there is lot of competition and for the growth and consistence, logistics needs to be at its best. Hence this study is taken out to analyze the effect of logistics management on the customer satisfaction in the retail sector of twin cities Islamabad and Rawalpindi.

\subsection{Research Significance}

Profitability of the business and hence it is quite evident that the profitability of the business is dependent on the satisfaction of the customer, as if the customer will be satisfied then it is quit evident that the customer will visit more and hence more sales will result more profitability. Now in all this logistics plays a very important role and this study will analyze the impact of logistics management on the customer satisfaction in the retail industry in the twin cities of Islamabad and Rawalpindi. This study will also help in the academic realm, and will assist them in the getting to pool of knowledge about the impact of logistics on customer satisfaction. The retail sector can also be benefited from the study, as the study will help them get substantial findings on the impact of logistics on customer satisfaction. Other companies especially in the service industry will be able to understand the significance of logistics in improving the level of customer satisfaction. Supply chain practitioners will benefit from this study since it studies supply chain management in service sector.

\subsection{Problem Identification}

Logistics is responsible for the planning, then implementing and then controlling the efficient and effective flow and also storage of goods and services in any 
supply chain, along with the goods and services the flow of information from the origin to the flow of consumption is also included. Consumers always demand goods and services in time and most importantly in a cost-effective way is always an important question in the retail sector. Retail stores are always in need of smooth flow of goods, in time and availability of the inventory and which means that the logistics plays a very vital role like what will be the route and medium through which the goods can reach in the most cost effective way and in time. As if there will be any delay for the goods to reach the store or the cost increases then the customer will be dissatisfied will switch to the competitor. And as the main objective of every organization is maximizing the profitability and along with the profitability the performance of the organization should also at its best so that the customer can be satisfied, who's satisfaction will result in the profitability of the organization. And keeping everything timely and available is much difficult for the retailer'. So this study is going to address the impact of logistics performance on the customer satisfaction in the retail sector of the twin cities Islamabad and Rawalpindi, by taking into consideration the four most important factors inventory, lead time, transportation and logistics management The inadequate control on the management of the logistics including factors like inventory, lead time, transportation and logistics management can be the reason of poor quality services to the consumer, which will dissatisfy the consumer and the profitability of the organization will be affected highly.

\subsection{Research Questions}

These questions will be addressed in the research which will be conducted,

$\checkmark$ What role logistics management plays for customer satisfaction in the retail sector?

$\checkmark$ What is the importance of logistics management in satisfaction of customers in retail sector?

\subsection{Research Objectives}

The objectives of this study are,

$\checkmark$ To examine the impact of logistics management on the customer satisfaction in the retail sector.

$\checkmark$ To examine the importance of the logistics management in the satisfaction of customers in retail sector.

\section{Literature Review}

\subsection{Concepts and Definition}

\subsubsection{Customer Satisfaction}

According to Eckert 2007, the satisfaction of customer the number of customers an organization have in many terms like the size of customer's pool, the quality of them and then not but not the least the loyalty they have with the organization. Now customer satisfaction can be measured based on his loyalty and re- 
purchase from the organization, and these are among many other ways that an organization apply to serve its customer through the information system and the alliance of the customer [9]. As per Eckert 2007 satisfaction is reference to the product quality along with the services and the relation between the price and performance and along with all these it also is when an organization is right on top of the expectations of the customers and also going beyond those expectations. There are certain terms from which an organization can recognize the customer satisfaction, which can be the time taken for the delivery and also according to the specification of the customers [9]. Other variables like the needs of the customers, how early a product can be in hand to fulfill those customer needs, partnership and relationship with the suppliers, which is, the information sharing about sales, future sales, the stock of inventory to be kept, and reliable and interconnected data, which will act as a helping hand in overall inventory management, all this has been studied by Lee \& Kleener, 2001 [10]. Satisfaction is related to the fulfillment of the wants of the customer, and in the eyes of organization it means that does the product or service is fulfilling the wants of the customer or not, if it is then the customer will be satisfied, which also includes the stages to the fulfillments which can be over or under both. If an organization wants to obtain high level of satisfaction in its customer, they are required to provide not only quality products but superior products. According to Hendricks 1997, it is very important before the purchase of the product weather the customer is satisfied or not. A study conducted by Wicks \& Roethlein 2009 reported that any organization can be consistent in satisfying its customers, and customers will be retained with the organization which will result in more profitability only if there are more and more loyal customers [11]. And for making this happen organizations are working harder than ever as there is more of competition, to satisfy their customers by their loyalty, which will resultantly increase in the number of sales and profitability as well. Whenever the customer's perception about any brand is good then it is an obvious fact that he would always want to avail the brand, because that brand has made its image and perception in the mind of the customer and he would always go for. As a research conducted by Hague \& Islam 2013, the selection of brand by customer will depend on the customer upon the perception and satisfaction level given by that brand by his prior experience with the brand, and if the experience is good he would always go for that brand [12]. As the customer satisfaction has the direct influence on the sale of the customer and it plays a very important role in the businesses, so researchers are emphasizing this allot in their research that how the customers can be more satisfied by the business. And as this issue of satisfying the most important stakeholder of the business which is customer, who also is the most unpredictable, and is one of the stakeholder of the business due to which the operations runs in business and the businesses operates due to it and satisfaction changes according to the values and behaviors of the individuals this area is of main concern and research. As the environment is changing day by day and the competition increases in the environment, organizations must cater 
all these changes timely, studied by Zhang 2005 [13]. Zebrine et al., 2007 describes the ultimate objective of profitability, customer satisfaction is the main factor. Now day's organizations are focusing on the customer satisfaction, which also shows the competitiveness of the organization [14]. As per Rad 2008, the flexibility of SC partners is the main factor on which the satisfaction of customer relies.

\subsubsection{Inventory}

Sterman and Dogan 2015, study mentioned the term inventory management which is one of the main terms used in SC and then it also tells that the stock which includes all the types and forms including work in progress and finished goods both of them are kept at such a level that we should provide maximum services at the minimum costs [15]. According to Silver et al., 1998, inventory management is the main factor for many firm's success, and the fate of the company, meaning the future's success and how much the company will be sustainable in the future will depends on the inventory and its management. Inventory has got many costs associated with it like transportation costs, holding costs and management costs; if not well maintained and planned then it would result in high costs for the firm itself and resulting in the customer dissatisfaction [16]. According to Chambers, Lacey, 2011, there always is a competition among the benefits of holding the inventory which will be taken in future and the cost of keeping the inventory, when it comes to the benefits then at the time of need the goods availability, and when it comes to the costs it involves the opportunity cost which means that the finance which has been used for getting the inventory, ordering it and handling it [17]. The management of inventory means the benefits of the inventory and cost of the inventory and having the maximum profit out of the inventory. A study conducted by Shim, Siegel 2007, it has been stated that the levels of inventory is the main factor which involves the cost for the storage of the inventory, the insurance paid for it, spoilage and last but not the least the interest which is paid for the acquiring of the inventory [18]. And an another study conducted by Shim, Siegel 2008, it has been stated that success of management of inventory gets the lower level of inventory meaning the minimization of inventory, decrease of cost of increase in the profitability, managers are the one who will find the adequate level of inventory level in the organization, as the inventory level by manager depends on many factors like sale, conversion speed into cash, amount available for getting the inventory, production, the reliability of suppliers and many other factors [19]. As we have inventory levels high then the sales cannot be lost and also increase the production outputs, as due to the availability of inventory. Inventory levels are also affected by short term interest rates which mean that as the interest increases the level of inventory in holding is reduced it will incur more cost. As in the environment now a day there is a lot of competition, so this kind of environment inventory and services both are a major factor for the inventory management to be concerned about. They both can be very harmful for the business as bad services can result in the 
loss of customers and high inventories can result in incurring cost including holding cost and many others, this has been studied and explained in Hübner et al., 2013 study [20]. The true essence of management of inventory is to argue that the operations of the business to seamless flow of goods, product and services Chaltora 2013 [21]. So if we look at this it can be easily understood that inventory is a broader term, there comes a lot of things in inventory as the total quantity of goods available in the stock of the company, now this stock contains a large amount of goods and materials-including office supplies like stationeries, plant, machinery and many more Stephen and Gupata, 2016 [22]. A study by Sterman and Dogan 2015, explains that as the suppliers are given orders and they have to fulfill the orders but if they fail to do so then in result the delivery will take longer time and the service to the customers becomes more and more poor day by day if this keeps on happening [15]. So, for the understanding of the replenishment scheme of retail sector, periodic review system is applied. These systems are designed for the order placement of different sizes, periodically, which automatically takes the inventory levels to the required level, stated by Waters 1999, in his study, the best example of this can be in a retail stores in which the shelves are replenished periodically as say at the end of the day [23]. As this is periodically and continuous replenishment on a regular basis, so this best suits the low cost stock but with the low cost but the demand is high which results in low inventory management cost. As studied by Egg and Reiner (2007), the investment increases due to increase in inventory levels that increases the opportunity cost. Retailers for this reason will have to maintain an optimal level of inventory, so that they can meet the customer demand and also the services level should be at its best the products which are high in demand should be replenished [24]. According to Eltantawy et al., 2015, if inventory, safety stock at buyers facility needs to be reduced and development reliable of forecasts along with decreasing the lead time for the products, if all this is needed then the supply chain in any organization or retail sector should be coordinated [25].

\subsubsection{Lead Time}

In the context of supply chain lead time is defined as, whenever customer place an order for any product or services then from the time the customer orders to the time customer receives the product or services is called lead time, if it is not final product or an intermediary (say work in progress), so here lead time is the time taken to actually manufacture the order without any inventory other than raw material, if it studied from the point of view of manufacturing then it is very simple that the definition will remain the same but it will also incorporate time taken by the supplier to ship the raw material, stated by Job Louis Mfwaya 2013 [25]. Lead time is the time which is spend between the ordering and the receiving the order, the time can be different for different products as it depends on the nature of the product as products can be made to order or it can readily be available for the shelf. Nordas et al., 2006 [26], there are number of factors on which lead time matters like SCM, the planning, the logistics management and 
the remoteness from customer to the supplier. If the delivery is known and also demand is known then lead time is not a problem as everything is known, but if demand is not known then lead time is costly even though the customer knows about the delivery. If the forecasting is not done accurately then lead time can create problems as products are not on the shelves resulting in the loss of the customers and also loss of sales indirectly. And if there the forecasting is not done properly and the future demand is overstated then it will also be result costly as first of all there is high holding cost and the products on shelves will take longer then they will be sold on discounts. So according to Nordas et al., 2006, if the lead time is high and the substitutes are also high then large amounts of products is needed. That also requires the level of safety stock to increase, due to which the cycle time increases and the forecasting becomes less and less accurate [26]. The difference in lead time can incur for items which are in the purchased list and the ones which are manufactured in house. According to Zhang 2008 , one of the factor which is the reason for longer lead time is the machine breakdown, as the machine repairing will take time and results in longer lead time [13]. The most important factor which effects lead time variability is planning. As Alp and John 2003, stated that when inventory is kept at different points in supply chain then it will work as reducing the risk factor when there is variation in demand. According to Atallah 2005 as there is globalization and there is a global economic integration, companies are creating alliances. The concepts of national borders are decreasing and trade has increased all over the world. So all these developments requires the mode of transport to be changed as this will also affect the lead time [27]. Atallah 2005, further continued that as there is a huge development of the containerization, which results in introduction of multi model transport cargo system of "door to door" than port to port [27]. In a study conducted by Hopp et al., 1990, it is stated that just in time in supply chain management is the reason of smooth workflow as it reduces the inventory levels and lead time both. Lead time variability can be reduced if the work is done in small amount as this will also result in even workflow [28]. According to Teimoury et al., 2011, supply chain management is the network of organization which starts from the supplier of raw material and ends at the customer, so supply chain incorporates all the parties which create value resulting in the satisfaction of customers [29]. And supply chain incorporates the transporters, retailers and the customer as well. And as the supply chain gets more and more difficult because of demand fluctuation, which results in the variability of the time taken for the processing. When the queue control and its management is done effectively in the organization then uncertainty also reduce.

\subsubsection{Logistics Management}

A study conducted by Waterz, 2003, there are many functions involved in any organization, but there is a function which is called logistics which has the responsibility of the flowing of materials from the supplier into the organization, through the operations within the organization [23]. In the same study Waterz 
2003, also stated that almost every organization move material from one point to another point, this operation is the main factor which is the reason of value creation in any organization, and then operations for the conversion of raw material into finished goods and then after finished goods are produced, then those finished goods are delivered to the customers [23]. So the material which comes into the organization form the supplier is called the inbound or inwards logistics, and on the other hand the material which is sent out of the organization to the customers is known as outbound or outwards logistics. So may it be inward logistics, or may it be the movement within the company or the outward logistics, all this comes under logistics. A study conducted by Calipner, 2007 [30] sometimes there are other materials while transporting including pallets, delivery boxes, cable reels and containers all there are returned to the supplier as these are reusable. While there are other materials, which are not reusable, but they are given back to the supplier, for the reason of the recycling including metals, glass, papers, plastics and oils. And then there are materials which are not either brought back for reuse or recycling but for safe disposal which includes dangerous chemicals. And such activities which bring back the materials to the organization is known to be the management of reverse logistics or reverse distribution. According to Bowersox et al., 2007, the creation of value in the supply chain of any organization is due to logistics management in different ways like management of the services to the customer, orders stocks, the shipment and transport services, storing, the handling, information, forecasting, procurement, cross docking, direct delivery, warehousing and distribution [3]. According to Bowersox et al. 2007, the creation of value in the supply chain of any organization is due to logistics management in different ways like management of the services to the customer, orders stocks, the shipment and transport services, storing, the handling, information, forecasting, procurement, cross docking, direct delivery, warehousing and distribution [3]. According to Zhang 2005 , as logistics management is not at one location because at times the locations are different as in any organization the stock of the finished goods are stored after all the process is done on it, and then the moving of finished product to the warehouse, and the transported to the stores where customers can see it, as there are number of activities and logistics has to find the most appropriate locations for these, or if logistics don't find a good location for it then it would have to play a vital role in the decisions to be taken [13]. In the same study Zhang 2005 also stated that it's not only the physical flow of products but also the flow of the information, which is the reason that the whole supply chain linkage [13]. In a study conducted by Frohlich and Wetbrook 2001 [31], the logistics integration is the coordination at its best, while passing of materials from the starting point generally the supplier, which is basically the reason of have a smooth process. Coordination results in the seamless connection of the organizations and suppliers, and due to that they becomes so much integrated that the differentiation of the activities becomes blur. Londe and Masters 1994 [32], logistics management is such a factor for any organization, that due to its integra- 
tion organizations can enjoy the benefits of having a vertical integration (quality, dependability, planning and control and lower cost), as it does not exists in the real sense but due to logistics it is possible.

\subsection{Relationships between Variables}

\subsubsection{Inventory and Customer Satisfaction}

A study conducted by Christopher 2011, says that as the paradigm of organization has changed from product focus to customer focus, so after the change now the businesses are focusing on the processes which caters the demand of the customers, because customer is now more aware and educated [33]. Due to lot of competition and as there are substitutes available for every other product, then the demand which comes from the customer requires diversification and then to cater the diversified demand, policies of the organization also needs to be in relevance. According to Eckert 2007, every organization wants to be in the market with a sustainable growth, and for that its customers' needs to be satisfied, and inventory availability and its management is the main factor which results in the customer satisfaction as there is strong connection between them [9]. A study conducted by Widing 2003, says that due to the intense competition customers wants the product in shortest possible time and with high quality, and the right product, and when an organization provides all this then the customers will be satisfied, for all this to happen the suppliers needs to be in strong connection because they will make the required inventory available in the given time period [34]. And when the organizations want to satisfy the customers, for this the members of supply chain needs to accumulate and maintain buffer stock. And all this result in the organization and supplier in long term relationship, and due to the long term relationship, the supply chain of the organization will be more sustained. According to retail historian, Robert Spector, good inventory system is one of the main factor to consider in the retail sector. A study conducted by Levinson 2005 [35], demand forecasting will never be accurate if the retailers don't have a good inventory system incorporated, and if the forecasting will not be accurate them they will experience inventory stock outs. When there is no inventory available for the customer then the customers will go for the other stores which will result in the loss of sales and also the customer will not be satisfied. The study conducted by Ogonu Gibson Chitru et al. 2016, investigated that inventory management has a strong positive relation with the satisfaction of the customers. This study was conducted in the retail super markets of Nigeria. And this study was conducted by the use of Likert scale questionnaires, and the sample size was 50 super markets and from each super market there were total 10 respondents, which makes it a sample of 500 and out of this 500 sample data the percentage of useable data was 80 . The tests which were applied on the data was Cronbach alpha and spearman's ranking correlation statistics. And the result which they got from the data after applying tests that determinants of inventory management like inventory management, information technology both influence the customer satisfaction a lot, and the third determinant 
in the study which was strategic supplier partnership was a weak factor in determining the satisfaction of the customers [36]. So therefore, the study recommends that the inventory management in the super market of Nigeria effects positively the satisfaction of the customers. Drawing on these evidences it is hypothesized that:

H01: There is a positive relationship between inventory and customer satisfaction in the retail industry of Pakistan.

\subsubsection{Lead Time and Customer Satisfaction}

The economy nowadays is global, and for the organizations it is very important to know that consumers are more educated and sophisticated than before. They always demand high quality products and services, in less time because they have resources for them. And now as it the time for extreme competition, organizations needs to provide high quality products and services, in short time to the consumers and capture more and more market share and due the high quality product and services satisfaction of the customers is increased Mfwaya, 2013 [25]. The factor which decides for the purchasing a product or services has changed from only price to reasonable prices along with high quality and services, along all this lead time needs to be minimized as well for the satisfaction of the consumer (Kimberley, n.d.). The satisfaction of the customer is shown from the reaction from the customer after purchasing or using the offerings of the organization which has offered to him. In his study he elaborated as well that the customer's reaction is the main factor from which his satisfaction can be known and also the customer's perception of the received value by using the product. A study conducted by Blackburn et al. 1992, says that the customer of the current era wants the best product, with high quality and services, at whatever place they want it, in how much time they want it, and all these things with reasonable prices [35]. Blackburn et al., 1992 also stated that the customers nowadays are in market with lots of substitutes meaning the competition is very high, so now the organizations are not only focusing on the product but also the services of the product as well, which will end in the value creation along with the product and these value additions can be in form quality and delivery time [35]. According to So and Song 1998, in the market there is a lot of competition, and every organization wants to achieve competitive edge, and that competitive edge is short lead time, as short lead time will play a vital role for any organization to have the competitive edge for the organization, and the organization will stand out in the market, due to which the customer will be more satisfied and result in more sales [36]. According to the study conducted by Job Louis Mfwaya 2013, to examine the relationship and effect of lead time management on the customer satisfaction in the telecom sector of Kenya [25]. In this study the sample was of 160 respondents. Including the managers of the companies and the service providers in the country, the study uses a cross sectional survey, and the variables which are taken as independent variable are multiple transport system, expediting the orders, reducing variability and lead time and the dependent variable is customer satis- 
faction, and after applying statistical analysis like Cronbach alpha, correlation and regression the result of study indicates that there is a significant strong positive relationship between all the four independent variables and dependent variable. H02: There is a positive relationship between lead time and customer satisfaction in the retail industry of Pakistan. According to Bowersox et al., 2001, transportation is such a factor which plays a very vital role in interlinking the different components of the organization, and if the coordination and management between each component of the organization will be good then it would benefit the logistics, which will also improve logistics efficiency, reduce the cost of operation cost and provide quality services to the firms which will create value for the organization and its customers, and the customers will also be satisfied [3]. A study conducted by Larid 2012, stated that the value of the product is more increased and maximum when it is in the retail store in time than the same inventory in the warehouse as it offered for sale in the retail store, as in retail store the customer needs are fulfilled if the product is there in time [36]. In the same study Larid 2012, also stated that transportation play a very vital role and adds value, as in the warehouse the product wait for its transportation to the retail store, where it generates the revenue and also satisfy customers [36]. A study conducted by Mwangani 2016, investigated that transport management has a strong positive relation with the performance of the firm. This study was conducted on the manufacturing firms. The sample size was 320, which was more than 10 percent of the whole population, and the data was collected through questionnaire using Likert scale, and the tests which were applied on the data was correlation and regression was applied and the error rate was .05, there were four independent variables namely transport management inventory management, order process management and information flow management and the intervening variable logistics information system and their impact on firm performance and all the results were positive.

H03: There is a positive relationship between transport management and customer satisfaction in the retail industry of Pakistan.

\subsubsection{Logistics Management and Customer Satisfaction}

The most important factor in the buying decision of the customer is logistics, and not only the decision of the buying but also of visiting the retailer again also is affected by the logistics. A study conducted by Johnson 2004, says that the retailers who in future will have seamless and versatility of the access will be successful, because retailers will be fulfilling all the requirements like where customers wants them to be, at what time they want them, and how they want to deliver [37]. According to Patrice et al. 2003, customers are becoming educated now and in result they might have variance in the mode of delivery, and their expectation levels also can be different as the services which they need and demand will be different, so for that logistics management plays very important role. The study conducted by Ltifi and Gharabi 2015 [38], investigated the effect of logistics performance on customer satisfaction in the retail store, during the 
study it is said that the old ways of getting a competitive edge which is from price, product and promotion is not effective that much now, because logistics plays a very role in the value creation for the customer which makes them more happy and satisfied, the sample size was of 180 respondents from the city of $\mathrm{Tu}$ nisia, questionnaire were used to gather the data from the respondents and those questionnaire were based on Likert scale, and to measure the satisfaction the model of Oliver (1980), was used. And the variables which were included in the research were inventory stock outs, product information, returns and ease shopping and their effect on the satisfaction of the customer, and the results stated that the logistics performance effect positively the customer satisfaction in the retail sector.

H04: There is a positive relationship between logistics and customer satisfaction in the retail industry of Pakistan.

\subsection{Theoretical Reflections}

This is the chapter where there is theoretical support, on which the research is based. This support will be including unified theory of logistics and satisfaction theory as well. Its relationship with the above stated theories with the study is explained at the end of the explanation of every theory.

\subsubsection{Unified Theory of Logistics}

In the study conducted by Mentzer et al., 2001, proposed a unified theory of logistics basis on the firm theories for the organization, and the first theory of firm was identified by (Holstrom and Tirole, 1989) and as more theories of firm evolved, the need for a unified theory of logistics was felt and then Mentzer et al., 2001, developed this theory and one of the explanation of the unified theory of logistics is that there should be goal regarding competitive advantage of the organization which is continuous customer value creation for the satisfaction of the end users [39]. The review of the theories of the firm results in the explanation of the role of the logistics which includes the providing of boundary-spanning, coordinating capabilities regarding demand and supply as the organization main goal is to create profit and which is always related to the value creation in the eyes of the customer which results in the satisfaction of the customers. As every firm wants effectiveness and efficiency incorporated in it, so the effectiveness and efficiency in terms of logistics which will result in competitive advantage is efficiency (cost leadership), and effectiveness (customer services). The factors which are included in the capabilities of logistics regarding competitive advantage are interface capabilities (customer services and logistics quality), supply chain management interface capabilities (low cost supply and distribution), and information management capabilities (information sharing via information technology and connectivity).

\subsubsection{Transportation and Customer Satisfaction}

Mentzer et al. 2001, the competences of logistics plays role of a major factor in 
boundary-spanning interfaces between areas of internal functional and also between other supply chain partners of the firm. When the logistics and marketing function of a firm are both in coordination then this can offer unique and different products or services for fulfilling the requirements of the customers [39]. In the same study Mentzer et al. 2001 also stated that when there is an incorporation of logistics in the production of then there is decrease in the cost and also the decrease in the expenses, and all this reduction with providing quality customer services which results high customer satisfaction [39]. And the second factor which is coordination of logistics and other supply chain partners of the firm which are suppliers, distributors and other intermediaries, and this coordination results in the creation of customer value, and also the benefits are shared. So logistics is the internal part of the larger concept of supply chain management. The logistics of the retailers which includes the internal logistics and external logistics plays a very vital role in the satisfaction of the customers as it the only factor which is between the organization and the customers acting as an intermediary, this is stated in a study conducted by Samli et al. 2005, leading to "cognitive evaluation of services experience [40]. A study conducted by Mentzer et al. 2001, the factors which plays the main role in the customers satisfaction and the creation of value is timely availability, and availability of the products and the conditions of delivery, and all these also play the role of the criteria for the evaluation of the customers is logistics operations [39]. In the same study conducted by Mentzer et al. 2001, logistics is one of the factor which creates the value for the customers in terms of ease, and saving of time, through an effortless interaction with the retail services [39].

\subsubsection{Expectancy-Disconfirmation Paradigm (EDP)}

Oilver (1980), Expectancy-Disconfirmation Paradigm (EDP) act as the most capable theoretical framework for the assessment of the satisfaction of customers. As per this paradigm, a consumer always come again for the purchase of goods and services, as they have in their mind the pre-purchase experience which will act as the anticipation of the performance of the goods and services. Then as the expectation is set in the mind of the customer creates a certain level about the performance, and now this level will act as a standard according to which the product and services will be judged after the consumption or use of the product and its comparison with the set level. And there are two outcomes which can be the matching of the expectations of the customer with the set level, which results in the conformation of repurchase and if it doesn't matches then it results in the disconfirmation as the performance and the expectation are not same. This paradigm notes the satisfaction or the dissatisfaction of the customer, as a result of positive and negative comparison between expectations. There is a positive confirmation if the services or the product has provided more than the expectation of the customer or equal to the expectation level resulting in the satisfaction, and on the other hand if there is a difference between expectations of the customer 
and the services or the product and they are not matching then the result is negative, and this negative result as a dissatisfaction of the customer Satisfaction is a function of positively evaluating the quality and value of service elements. The comparison which customers does is between the past experiences with the retailer's performance and the desired outcomes and expectations.

\subsection{Theoretical Framework}

The conceptual framework which will be addressing the issues in the research will be focusing on the effect of efficient logistics in the retail sector. There are always two main variables including the Dependent Variable which will be effected by the other variable called Independent Variable (Figure 1). Independent Variable that is always manipulated by the researches to investigate whether it convectively bring changes to another variable. This other variable, which is measured and predicted to be the dependent upon the independent variables, here the Inventory, Lead Time, Transportation and most importantly Logistics Management is mearusered as IV which consecutively bring changes on customer satisfaction in retail stores in either ways as the comfort are discomfort zone of the satisfied or dissatisfied customer.

\section{Research Methodology}

\subsection{Research Design}

The design of this study will be with minimum interference, cross sectional descriptive survey. The reason for choosing this type of survey is that it will be the most appropriate for this research and its questions. This survey which is known as cross sectional survey will enable the researchers to examine the effects of logistics on the customer satisfaction, in the retail sector of the twin cities of Islamabad and Rawalpindi. And this study will also offer the opportunity for a logical structure of the inquiry into the problem of the study. This is descriptive study along with hypothesis testing on the impact of logistics on the customer satisfaction in retail sector of the twin cities, and the basic research will be

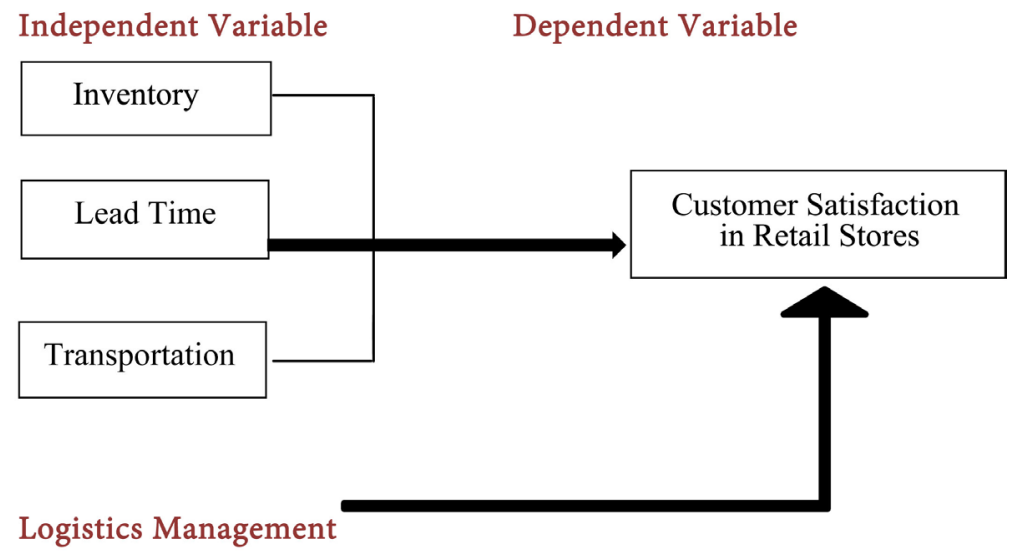

Figure 1. Theoretical framework. 
revolving around the major factors like lead time, transport management, logistics and inventory which will improve the customer satisfaction of the retail store. The research is based on two types of data secondary and primary data. The secondary data is the literature review and the theory support and the data obtained from the survey through the questionnaire is known to be the primary data for this study.

\subsection{Population and Sampling}

According to the report issued by Punjab board investment and trade there are almost 2500 retail stores which are operating in the twin cities and they have plans for expansion, the stores which are considered in this research are namely Cash and carry, Bojaz cash and carry, Metro Cash and carry, Save mart, Madina Cash and carry, Chaudhary cash and carry, Classis departmental store, S Attaullah Departmental store, Hafeez departmental store, Happy departmental store and Saudasulf located in Rawalpindi and Islamabad. These departmental stores are having branches all over the twin cities in different sectors in Islamabad and areas of Rawalpindi. And in all these stores total of 230 questionnaires were distributed out of them 200 questionnaires were returned. There are control variables also included in the research which are total four in number, including the location of the store, age of the respondent, presence of the department of the logistics/SCM in the store and the educational level of the respondent, as all these play roles in the finding of the study?

\subsection{Data Collection}

The data was collected through structured questionnaires, this instrument is adopted from Min and Mintzer et al., in 2004 [41], and the respondents were the logistics manager, and when the logistics manager was not present then these questionnaires were filled by the inventory and ware-house manager and even when they were not present then the questionnaire were filled by the store manager who also had knowledge of the logistics.

\subsection{Measuring Instruments}

Current study is focused on logistics, which includes the following factors; transportation, lead time, inventory and logistics. The value of Cronbach's alpha is the factor in every research which proves the reliability among the research questionnaire items, and minimum acceptable value of Cronbach's alpha is 0.7 , the factors of logistics were measured as follows.

\subsubsection{Transportation}

This factor is measured by using a five items instrument, and this instrument is adopted from Min and Mintzer et al., 2004 [41], and it's from SCM. Its uses a Likert 5 scale which uses the following categories, 5 which is equal to Strongly agree, 4 is equal to agree, 3 is equal to neither agree nor disagree, 2 is equal to disagree and 1 is equal to strongly disagree. 


\subsubsection{Lead Time}

This factor is measured by using a five items instrument, and this instrument is adopted from Min and Mintzer et al. 2004 [41], and it's from supply chain orientation (SCO) and considerable research has shown that SCO is reliable and valid. Its uses a Likert scale which uses the following categories which are, 5 which is equal to Strongly agree, 4 is equal to agree, 3 is equal to neither agree nor disagree, 2 is equal to disagree and 1 is equal to strongly disagree.

\subsubsection{Inventory}

This factor is measured by using a five items instrument, and this instrument is adopted from Min and Mintzer et al., 2004 [41], and it's from supply chain orientation (SCO) and considerable research has shown that SCO is reliable and valid. Its uses a Likert scale which uses the following categories which are, 5 which is equal to Strongly agree, 4 is equal to agree, 3 is equal to neither agree nor disagree, 2 is equal to disagree and lis equal to strongly disagree.

\subsubsection{Logistics Management}

This factor is measured by using a five items instrument, and this instrument is adopted from Min and Mintzer et al., 2004 [41], and it's from supply chain orientation (SCO) and considerable research has shown that SCO is reliable and valid. Its uses a Likert scale which uses the following categories which are, 5 which is equal to Strongly agree, 4 is equal to agree, 3 is equal to neither agree nor disagree, 2 is equal to disagree and 1 is equal to strongly disagree. Dependent Variable which is customer satisfaction is measured as following.

\subsubsection{Customer Satisfaction}

This factor is measured by using a five items instrument, and this instrument is adopted from Min and Mintzer et al., 2004 [41], and it's from supply chain orientation (SCO) and considerable research has shown that $\mathrm{SCO}$ is reliable and valid. Its uses a Likert scale which uses the following categories which are, 5 which is equal to Strongly agree, 4 is equal to agree, 3 is equal to neither agree nor disagree, 2 is equal to disagree and 1 is equal to strongly disagree.

\subsection{Data Analysis}

For the analysis of the data collected, the analysis will be done on the Statistical Package for social sciences (SPSS), as it is the descriptive research, so on the basis of the data collected through questionnaires, their percentages, mean and standard deviation calculation will be done. As already explained the analysis used will be descriptive, due to applying this, the re-searcher will be enabled for the summarizing, organizing, evaluating and interpreting the numerical results from SPSS. And regression analysis will be applied for creating the relationship between the factors of logistics and customer satisfaction.

\subsection{Statistical Tools for Data Analysis}

After collecting the data, the following tests are applied, for the internal consis- 
tency, in other words reliability of the questionnaire, Cronbach's Alpha is measured. For measuring the relationship between the variables, the correlation analysis is used. And for the relationship between the dependent and independent variables regression analysis is used.

\subsubsection{Cronbach's Alpha}

Cronbach's alpha, is the coefficient of consistency or reliability, it's a technique to check and compute the internal evenness between the questions or items used in the survey questionnaire, and it also determine the internal relation between the items of the questionnaire. According to Tavakol and Dennick 2011, the index of reliability, i.e., Cronbach's alpha takes measure of questionnaire items accuracy and validity [42].

\subsubsection{Correlation}

Correlation is the most common used statistical analysis to check the degree of association between any two variables. For the examination of the liner relationship Pearson correlation coefficient (r) is the most widely used measure. For its examination its value lies between +1 and -1 .

\subsubsection{Regression}

According to a study Field 2000, regression analysis is a statistical modeling used to estimate the type of relationship, and its intensity between predictor and outcome variable. In this study the model is applied on the independent variable those are inventory management, lead time transport management and logistics management and dependent variable that is customer satisfaction. The regression equation is given below

$$
Y=c+\beta_{1}(\mathrm{INV} 1)+\beta_{2}(\mathrm{LT} 1)+\beta_{3}(\mathrm{TRN} 1)+\beta_{4}(\mathrm{LOG} 1)+e
$$

And its explanation is given below

$Y=$ customer satisfaction (the dependent variable) $C=$ constant.

\section{Statistical Data Analysis and Results}

\subsection{Descriptive Statistics}

As of the total 230 questionnaires were distributed among the respondents of different retail stores in Islamabad and Rawalpindi, and out of those 230 questionnaires, 210 were received back from the respondents, and the analysis is done on 200, as 10 questionnaires were not filled completely, which makes response rate of $87 \%$.

\subsection{Demographic Profile of the Respondents}

The first part of the questionnaire, the respondents were asked to provide some personal information including their age, location of the store, whether there is a department of supply chain or logistics in the firm and information about their qualification is also gathered through the questionnaire. In the below detailed explanation the descriptive analysis of the demographic features are discussed 
along with their graphical representation.

\subsubsection{Location of the Store}

From the explanation given above (Table 1, Figure 2), it is evident that half of the stores for the research are located in Islamabad and half are located in Rawalpindi.

\subsubsection{Qualification}

The results (Table 2, Figure 3) from the demographics question from the respondent's shows most of them were bachelors qualified or masters qualified, and very few have only done matriculation and intermediate. In percentages, the highest percentage is $44 \%$, meaning that most of the respondents are bachelors, almost $33 \%$ are masters, only $4 \%$ are matric and $18 \%$ are intermediate passed.

\subsubsection{Age of the Respondents}

The respondents were also asked about their age, as from the above (Table 3, Figure 4) representation of the date on a pie chart and the numerical data given in the table above shows that there were total 200 Respondents, and out of those 200 respondents, the highest percentage of $44.50 \%$ are in the age bracket of 20 29 , and the second highest percentage lies in the bracket of 30 to 39 years which are $34 \%$, and the third highest percentage in age bracket is between $40-49$, which are $15.50 \%$ and the least is the highest bracket starting from 50 and above and the percentage in this age bracket is $6 \%$.

Table 1. Percentage \& location.

\begin{tabular}{ccccc}
\hline & Frequency & Percent & Valid Percent & Cumulative Percent \\
\hline Islamabad & 100 & 50 & 50 & 50 \\
Rawalpindi & 100 & 50 & 50 & 100 \\
Total & 200 & 100 & 100 & \\
\hline
\end{tabular}

Table 2. Qualification of respondents.

\begin{tabular}{ccccc}
\hline & Frequency & Percent & Valid Percent & Cumulative Percent \\
\hline Matriculation & 9 & 4.5 & 4.5 & 4.5 \\
Inter & 36 & 18 & 18 & 22.5 \\
Bachelor & 88 & 44 & 44 & 66.5 \\
Master & 67 & 33.5 & 33.5 & 100 \\
Total & 200 & 100 & 100 & \\
\hline
\end{tabular}

Table 3. Age of the respondents.

\begin{tabular}{ccccc}
\hline & Frequency & Percent & Valid Percent & Cumulative Percent \\
\hline $20-29$ & 89 & 44.5 & 44.5 & 44.5 \\
$30-39$ & 68 & 34 & 34 & 78.5 \\
$40-49$ & 31 & 15.5 & 15.5 & 94 \\
50 Plus & 12 & 6 & 6 & 100 \\
Total & 200 & 100 & 100 & \\
\hline
\end{tabular}


- Islamabad

- Rawalpindi

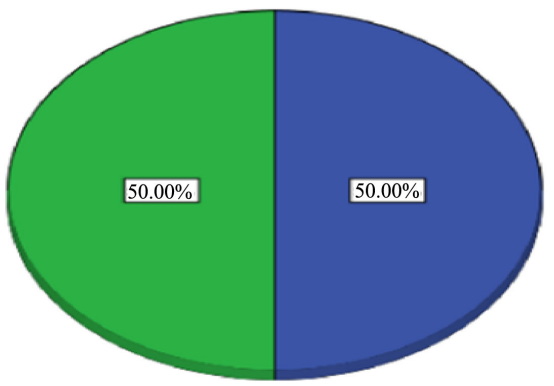

Figure 2. Percentage \& location.

- Matriculation

- Inter

- Bachelor

- Master

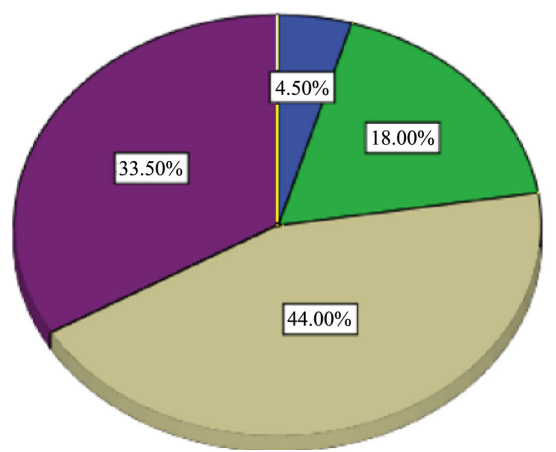

Figure 3. Percentage \& qualification.

- $20-29$

- $30-39$

- $40-49$

- 50 Plus

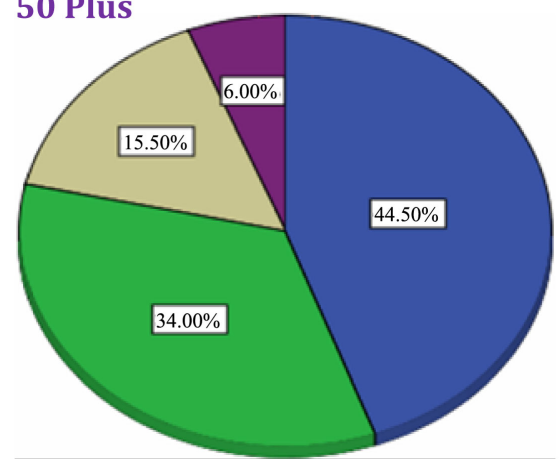

Figure 4. Percentage \& age.

\subsubsection{Department of Supply Chain/Logistics}

The results above (Table 4, Figure 5) shows the result of the question regarding the presence of the supply chain/Logistics department in the store and from the 
Table 4. Do you have logistic/supply department.

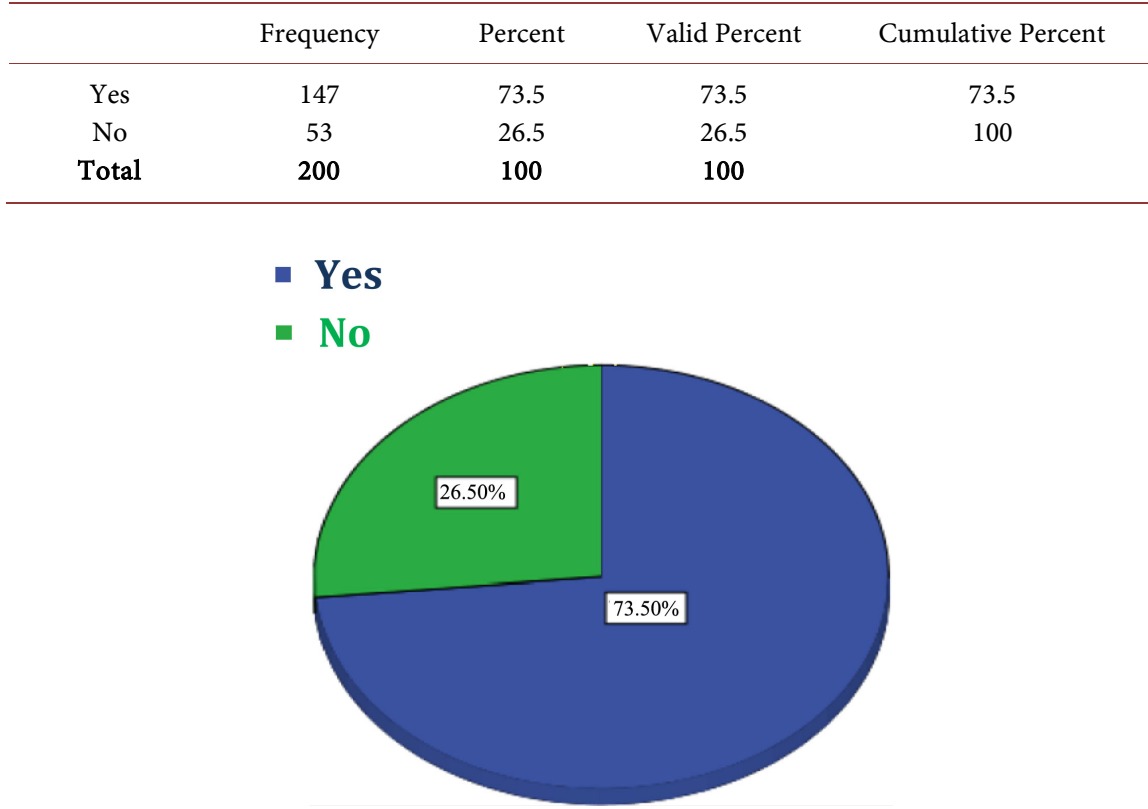

Figure 5. Percentage.

result it is shown that in total 200 stores there were $73.50 \%$ stores meaning 1477 stores which were having the department, and the rest 5 stores were not having any department.

\subsection{Reliability Test of Instruments/Scales}

Cronbach alpha is used to measure the reliability in other words internal consistency. Now as there are four independent variables and one dependent variable, and all are measured with a 5 items Likert scale questionnaire, which makes a total of 25 item, for all the five variables of the study. The reliability test is applied on each of the variable and the results through SPSS is given below in the Table 5.

As the minimum acceptable value of Cronbach Alpha is 0.5, and from the above table the values of all the variables namely inventory management having reliability of 0.912 , lead time is having reliability of 0.825 , transport management is having the reliability of 0.810 , the logistics has the reliability of 0.8366 and the last variable customer satisfaction is having the reliability of 0.809 and all these values are well above than the minimum requirement of reliability 0.5 , i.e. so this means this research can use this scale.

\subsection{Correlation}

\section{Correlation Analysis of the Study}

Whenever the liner relationship within two or more than two variables is measured, then the value of " $r$ ", known as the coefficient of correlation is used. The value of lies between -1 and +1 , and the answer is between these two ranges, and the value of an answer from applying this analysis is the representation of the 
Table 5. Cronbach alpha test scale.

\begin{tabular}{cccc}
\hline S. No. & Variable Name & Cronbach's Alpha & No Of Items \\
\hline $\mathbf{1}$ & Inventory & 0.912 & 5 \\
$\mathbf{2}$ & Lead Time & 0.852 & 5 \\
$\mathbf{3}$ & Transportation & 0.810 & 5 \\
$\mathbf{4}$ & Logistics Management & 0.836 & 5 \\
$\mathbf{5}$ & Customer Satisfaction & 0.809 & 5 \\
\hline
\end{tabular}

intensity of relationship between the selected variables. And the value " 0 ", represents no relationship at all. Now if the value is more than " 0 ", and it's towards +1 , then the relationship will be positive, and the value progresses towards +1 , the relationship becomes more stronger, and at +1 the relationship is perfect positive correlation. If the value is more than " 0 ", and its towards -1 , then the relationship will be negative, and the value progresses towards -1 , the relationship becomes more negative, and at -1 the relationship is perfect negative correlation. The signs "+" and "-", shows the positivity and negativity of the relationship among the variables in the analysis. For the determination of the direction and strength of the relationship among the independent variables of logistics management namely lead time, inventory and transportation and logistics on the dependent variable, customer satisfaction in the retail sector of the twin cities, the Pearson's Correlation test was executed through SPSS 20 (Table 6).

\subsection{Results of the Study}

The data from Table 1, shows the values of Mean, Standard deviation and correlation coefficient. Explanation of the data is as such that the mean the independent variables including inventory is 3.5080 , lead time is 3.5920 , transportation is 3.5040 , logistics is 3.4520 , and the standard deviation of customer satisfaction which is the dependent variable is .82425 .

The second tab in the table is of standard deviation, which are computed by SPSS with the following results, standard deviation of the independent variables including inventory $\mathrm{t}$ is 1.09248 , lead time is 0.88217 , transportation is 0.87419 , logistics is 0.79274 , and the mean of customer satisfaction which is the dependent variable is 3.5960 .

Table 1, also shows the results of Pearson's Correlation coefficient, and according to the results shown in the table all the variables are positively correlated among each other. The values which are shown in the table are for the dependent and independent variables. These result's explanation is in such a way that inventory and customer satisfaction have the value of $(\mathrm{r}=0.796, \mathrm{p}=0.000)$, which means that they are positively correlated, in the same way the results of coefficient correlation of the variables lead time and customer satisfaction is $(\mathrm{r}=$ $0.774, \mathrm{p}=0.000$ ) showing the positive correlation between both the dependent and independent variable. And the value of the variables transportation and 
Table 6. Means, standard deviations, and correlations test.

\begin{tabular}{lcccccccc}
\hline \multicolumn{1}{c}{ Variable } & Mean & Std. Deviation & 1 & 2 & & 3 & 4 & 5 \\
\hline 1. Invetory & 3.5080 & 1.09248 & - & - & - & - & - & - \\
2. Lead Time & 3.5920 & 0.88217 & 0.851 & - & - & - & - & - \\
3. Transportation & 3.5920 & 0.87419 & 0.641 & 0.742 & - & - & - & - \\
5. Logistics Management & 3.4520 & 0.79274 & 0.557 & 0.558 & 0.764 & - & - & - \\
6. Customer Satisfaction & 3.5960 & 0.82425 & 0.796 & 0.774 & 0.685 & 0.632 & - & - \\
\hline
\end{tabular}

Correlation is significant at 0.05 level (Where $\mathrm{N}=200$ ).

customer satisfaction is $(r=0.685, p=0.000)$, the last relationship between the last independent variable and dependent variable which are logistics management and customer satisfaction has a value of $(r=0.632, p=0.000)$. By examining all the figures above and the relationship between the variables through the figures, it is evident that inventory management, lead time, transport management and logistics are significantly positively correlated with customer satisfaction. Where the sample size $(\mathrm{N}=200)$ and the value of alpha $\mathrm{i}$-e $(\alpha=5 \%)$ is in the study.

From the above results, it is proved that the hypothesis, which were developed in the study are accepted which are (H01, H02, H03, H04). And the results of the correlation made it evident that the independent variables effect the customer satisfaction.

\subsubsection{Regression Analysis of the Study}

Regression is a predictive statistical analysis technique, and this analysis is used to find out whether the predicting variables predict the dependent variable (customer satisfaction), and from the existing list of predicting variables (inventory, lead time, transportation and logistics management), which variable significantly predict the dependent variable. So in other words it measures the percentage of change in dependent variable due to the independent variables.

SPSS V20 is used is used for the computation of the regression analysis of independent variables (inventory, lead time, transportation and logistics management) and dependent variable (Customer Satisfaction), and thee linear regression model is used to measure the impact of independent variables on dependent variable.

\subsubsection{Analysis Results}

Table 7 represents the numerical representation of the regression analysis, which shows the value of R-Square which is 0.707 , in percentage it will be $70.7 \%$, which means that the customer satisfaction is effected $70.7 \%$ by the inventory, lead time, transportation and logistics management, and the remaining effect is because of the unexamined factors which can affect customer satisfaction. The control variables which are also considered in the analysis are location of store, qualification, age and whether there is logistics or supply chain department in the store or not. 


\subsubsection{ANOVA}

The analysis of variance Table 8 sketched above illustrates about the fitness of the model, where the value of $\mathrm{P}$ is less than the required alpha value i-e $(\mathrm{P}<$ 0.05), which means that all independent variables (inventory, lead time, transportation and logistics) have their impact on the dependent variables (Customer Satisfaction).

Table 9 shows that the result after applying the linear regression analysis, which shows the impact of predictors and their contribution on the impact on the prediction of the of the outcome variable which is customer satisfaction in the study. After applying the regression analysis, the results which are obtained are that there is significant positive impact of inventory management on customer satisfaction, as in the numerical result it is shown as $(\mathrm{B}=0.330, \mathrm{P}=$ 0.000). The next variable Lead time has also a significant positive impact on the customer satisfaction $(\mathrm{B}=0.215, \mathrm{P}<0.05)$. The impact of transportation on customer satisfaction is also significantly positive. $(\mathrm{B}=0.080, \mathrm{P}<0.05)$. Similarly, there is a significant positive impact of logistics management on customer satisfaction ( $\mathrm{B}=0.202, \mathrm{P} \leq 0.05)$.

All the above stated results by regression analysis on the independent variables and dependent variables proves it that all the hypothesis is correct, and

Table 7. Model summary result.

\begin{tabular}{ccccc}
\hline Model & $\mathrm{R}$ & R Square & Adjusted R Square & Std. Error of the Estimate \\
\hline 1 & 0.841 & 0.707 & 0.701 & 0.48045 \\
\hline
\end{tabular}

Predictors: (Constant), LOGISTIC, INVENT, T_MGT, L_TIME.

Table 8. ANOVAa .

\begin{tabular}{cccccc}
\hline Model & Sum of Square & Df & Mean Square & F & Sig \\
\hline Regression & 95.630 & 4 & 23.908 & 117.827 & $0.000^{\mathrm{b}}$ \\
Residual & 39.566 & 195 & 0.203 & & \\
Total & 135.197 & 199 & & & \\
\hline
\end{tabular}

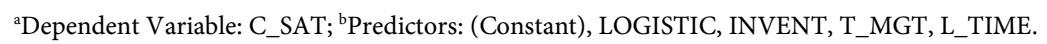

Table 9. Coefficients test.

\begin{tabular}{cccccc}
\hline \multirow{2}{*}{ Model } & Unstandardized Coefficients & $\begin{array}{c}\text { Standardized } \\
\text { Coefficients }\end{array}$ & $\mathrm{T}$ & Sig. \\
\cline { 2 - 4 } & $\mathrm{B}$ & Standard Error & Beta & & \\
\cline { 2 - 3 } Constant & 0.687 & 0.159 & - & 4.314 & 0.000 \\
Invent & 0.330 & 0.057 & 0.438 & 5.782 & 0.000 \\
L-Time & 0.215 & 0.080 & 0.230 & 2.675 & 0.008 \\
T-MGT & 0.080 & 0.071 & 0.085 & 3.135 & 0.025 \\
Logistic & 0.202 & 0.064 & 0.195 & 3.162 & 0.002 \\
\hline
\end{tabular}


there is strong positive impact of independent variables (inventory management, lead time, transport management and logistics) on dependent variable (Customer Satisfaction).

\subsection{Summary}

By examining the facts and figures and all the relationship of the variables it is proved that all of the variables are positively correlated with each other and have significant effect. And all of the Independent Variables Inventory Management, Lead time, Transportation and Logistics management bring changes in the Dependent Variable which is customer satisfaction where sample size is $87 \%$. And all of the hypothesis which are developed in the study are accepted and the IV have positive impact on DV.

\section{Discussion, Recommendations, Research Limitation and Future Directions}

\section{Discussion and Recommendations}

From the findings of the study, the researcher recommends that retail stores should focus on transportation, inventory, lead time and logistics, because they positively contribute to customer satisfaction. Policies and guide lines for multiple transportation systems and its management, inventory, reducing lead time and logistics management and their practices are also recommended to the retail stores. There is no adequately documented framework thus respective retail stores can, at their organizational level, formulate their logistics operations practices and policies. A framework will give logistics operations practices' guidelines to employees and how they can be integrated to their routine operations at a minimal cost. Retail stores should adopt the practices for reducing the lead time, inventory availability, transport management in logistics in their retail stores to ensure that right product quantities and qualities are available in the shelves at the right time. Removal of products which are not required by the customers is also very important, as new products can be placed in the shelves and which can contribute in the satisfaction of the customers. And also the shelves should be check daily for the replenishment of the products on the shelves, policies like these can help al lot in the customer satisfaction of the retail store. Also, the retail stores need to make sure that all the required inventory is available in time, and there should a minimum inventory level of every product according to its requirement by the customer, communication between the supplier and the store manager should be strong so that the lead time will be less and the transportation is managed according to required inventory, and the transportation should be managed in such a way that it should help in reducing the lead time, cost reduction and making the inventory available in time. It would be recommended that retail stores should ensure that they hold inventories at the lowest costs possible while ensuring stock adequacy, quality service and uninterrupted supplies to foster customer satisfaction. The retail stores should adopt a system 
that would ensure products are available within the store when they are needed without necessarily having them stored in the store, which means the transportation system should be so strong that the replenishment should be done as soon as possible to avoid any increased lead times, which would increase the satisfaction of the customers of the retail store. Orders should be expedited, when there is high demand, or if the inventory is low, which will negatively affect the customer satisfaction.

\section{Conclusions}

The purpose of this study was to analyze the impact of logistics management on the customer satisfaction in the retail stores, in twin cities of Islamabad and Rawalpindi. And to find out the importance of the logistics management in the retail stores which effects the customer satisfaction, for satisfaction of customers the variables which were used as the independent variables were inventory management, lead time, transport management and logistics management. In the study there were four hypothesis developed which were $\mathrm{H} 1, \mathrm{H} 2, \mathrm{H} 3$ and H4, and after applying all statistical analysis of correlation and regression and also after checking the reliability of the measuring instrument used, which in this study was Likert 5 Scale. The sample size was of 200 , and the study was conducted in the twin cities of Islamabad and Rawalpindi. And the results has supported the all the four hypothesis. As hypothesis 1 (H01) was accepted that there is a positive relationship between inventory and customer satisfaction, and it in conformity with the previous research, as in the study conducted by Ogonu Gibson Chitru et al. (2016), investigated that inventory management has a strong positive relation with the satisfaction of the customers in the retail super market of Nigeria. Hypothesis 2 (H02), which was the positive relationship between the lead time and customer satisfaction was also accepted, as from the previous studies is in conformity of this according to the study conducted by Job Louis Mfwaya (2013) to examine the relationship and effect of lead time management on the customer satisfaction, and the results from that study also shows a positive relationship between both the lead time and customer satisfaction hypothesis 3 (H03), which was of the positive relationship of transportation and customer satisfaction, this positive relationship was also supported by results of the study, as previous study of PatrickMwangani (2016), also confirms that there is a positive relationship between transport management and the customer satisfaction. And at last (H04), which was of positive relationship between logistics and customer satisfaction, and the results from the study have shown that there is a positive relationship between the logistics and customer satisfaction, and the hypothesis was accepted, as the previous studies are also in conformity, The study conducted by Ltifi and Jameleddine Gharabi (2015), investigated the effect of logistics performance on customer satisfaction in the retail store and the results from that study also showed that there is positive relationship between logistics performance and customer satisfaction. Performance was measured based on the customer satisfaction. This study therefore established that with transport man- 
agement provides better logistics efficiency, timely delivery, reduces operation costs and promotes services quality on firm hence bringing customer satisfaction when it comes to inventory, then for the customer satisfaction there should always be inventory available in the store so that the customer should know that he always can have all his requirements fulfilled in the same store, and which will make up his mind to revisit the retail store again. Customer will also be satisfied if there is less lead time in delivering the products and if the lead time is less than the store will receive its inventory in time, and making all the products available for the customer in time which can influence customers in a very positive way, resulting in their satisfaction. Logistics management is also is very important which is the reason of the value creation in the mind of the customer and the availability of the stock and not only availability but also the timely availability of the product and the delivery conditions as well and all these are the reason due to which a customer can be satisfied through the logistics of the organization. So it's proved that first of all there is a positive relationship between inventory, lead time, transportation and logistics management on the customer satisfaction, the study will help managers to improve the customers satisfaction of their stores, it can be retail store or it can be any other store which has logistics management involvement, these all create the value chain which results the satisfaction of the. Few studies are done for explaining the impact of logistics on the customer satisfaction of the firm in the retails sector of Pakistan, there are some researches done but some of the variables are missing from those researches as transportation was not incorporated. So, this study is a theoretical contribution.

\subsection{Limitation of the Study}

The instrument which is used for this study is survey questionnaire, and the survey done by the questionnaire is every time under criticism, as the finding done by this type of survey is less generalized. And the behaviour of human is not always the same, $100 \%$ accuracy is very difficult to find. So, the finding of the study cannot be declared pure form any type of business. The study is only done in the twin cities of Islamabad and Rawalpindi, so because of this the study is only limited to the twin cities, and as the culture is different and practices are different in other part of the region. The retail industry is a big industry, and the sample size of 200 is limited, this also is a constraint in finding better and generalized results for the study. Other variables also affect the customer satisfaction like behaviour of sales persons in store logistics and the warehousing, which is also creating a limitation for the study. AS this is a cross sectional survey, so for more generalized and accurate findings longitudinal studies should be done as it is necessary for the causal studies. At last the study is done only in retail sector of groceries, so this also is a constraint in the study.

\subsection{Future Recommendations}

As the study is only done in the twin cities of Islamabad and Rawalpindi, so for 
future researchers the study can be done in more cities in the region, which is a future direction for the future research on the topic. And the sample size that we select is only 200, which in future studies can be increased, and stores other than departmental stores can be taken into consideration like street retail shops etc. And the longitudinal study is also a future recommendation for the researchers. In future researches other variables like in store logistics and the warehousing should be considered in the model for the effect of logistics on customer satisfaction. For future research the industry can changed like the manufacturing industry.

\section{Conflicts of Interest}

The authors declare no conflicts of interest regarding the publication of this paper.

\section{References}

[1] Abbasi, M.N. (2013) Sustainable Logistic Operations-Study of Leading MNC from FMCG Sector of Pakistan. Pakistan Journal of Social Sciences, 33, 409-420.

[2] Alp, M. and John, N. (2003) Dynamic Lead-Time Management in Supply Chains. Graduate School of Business, Columbia University, New York.

[3] Aro-Gordon, S. (2016) Contemporary Inventory Management Techniques: Conceptual Investigation. Icomar, 1-20.

[4] Ayad, A. (2008) Optimizing Inventory and Store Results in Big Box Retail Environment. International Journal of Retail and Distribution Management, 36, 180-191. https://doi.org/10.1108/09590550810859141

[5] Armistead, C.G. and Mapes, J. (1993) The Impact of Supply Chain Integration on Operating Performance. Logistics Information Management, 6, 9-14. https://doi.org/10.1108/09576059310045907

[6] Ballou, R.H. (1997) Business Logistics-Importance and Some Research Opportunities. Gestão E Produção, 4, 117-129. https://doi.org/10.1590/S0104-530X1997000200001

[7] Board, P. and Investment, O.F. (n.d.) Report.

[8] Bowersox, D.J., Closs, D.J. and Cooper, M.B. (2010) Supply Chain Logistics Management. 3rd Edition, McGraw-Hill, Boston.

[9] Dubelaar, C., Chow, G. and Larson, P.D. (2001) Relationships between Inventory, Sales and Service in a Retail Chain Store Operation. International Journal of Physical Distribution and Logistics Management, 31, 96-108. https://doi.org/10.1108/09600030110387480

[10] Fang, Y. and Ng, S.T. (2011) Applying Activity-Based Costing Approach for Construction Logistics COST Analysis. Construction Innovation, 11, 259-281. https://doi.org/10.1108/14714171111149007

[11] Ghoumrassi, A. and Tigu, G. (2017) The Impact of the Logistics Management in Customer Satisfaction. Proceedings of the 11 th International Conference on Business Excellence, 293-296. https://doi.org/10.1515/picbe-2017-0031

[12] Gimenez, C. and Ventura, E. (2006) Performance Logistics-Marketing and External Integration Their Impact on Performance. International Journal of Operations \& Production Management, 25, 20-38. 
[13] Hamilton, T. (2015) The State of Logistics Performance Measurement: Comparison of Literature and Practice.

[14] Hoffman, K. and Hellström, D. (n-d-) Connectivity in Logistics Mngement: Frmework ND Supply.

[15] Kanja, D.W. and Mwangangi, P. (2017) Influence of Logistics Management on Supply Chain Performance in Retail Chain Stores in Kenya: A Case of Nakumatt Holdings Limted. The Strategic Journal of Business \& Change Management, 4, 425-444.

[16] Keller, S.B., Savitskie, K., Theodore, P.S., Lynch, D.F. and Elligner, A.E. (2002) A Summery and Analysis of Multi-Item Scales Used in Logistics Research. Journal of Business Logistics, 23, 83-28. https://doi.org/10.1002/j.2158-1592.2002.tb00027.x

[17] Lagat, C., Koech, J. and Kemboi, A. (2016) Supply Chain Management Practices, Customer Satisfaction and Customer Loyalty. European Journal of Business and Management, 9, 1-11.

[18] Laird, M. (2012) Logistics Management: Firm's Efficiency Performance Model. Unpublished BBA Thesis, Ohio University, Athens.

[19] Ltifi, M. and Gharbi, J. (2015) The Effect of Logistics Performance in Retail Store on the Happiness and Satisfaction of Consumers. Procedia Economics and Finance, 23, 1347-1353. https://doi.org/10.1016/S2212-5671(15)00516-X

[20] Lynch, D.F., Keller, S.B. and Ozment, J. (2000) The Effects of Logistics Capabilities and Strategy on Firm Performance. Journal of Business Logistics, 21, 47-67.

[21] Ogonu, G.C. and Mac-Kingsley, I. (2016) The Effects of Inventory Management on Customer Satisfaction: Evidence from the Supermarket Industry of Nigeria. International Journal of Marketing and Communication Studies, 1, 37-58.

[22] Mansidão, R. and Coelho, L.A.G. (2014) Small and Medium Enterprises Logistics Performance: A Theoretical Conceptual Model for Small and Medium Enterprises.

[23] Mentzer, J.T., Flint, D.J. and Hult, G.T.M. (2001) Logistics Service Quality as a Segment Customized Process. Journal of Marketing, 65, 82-104. https://doi.org/10.1509/jmkg.65.4.82.18390

[24] Mentzer, J.T., Min, S. and Bobbitt, L.M. (2004) Toward a Unified Theory of Logistics.

[25] Odoom, C.K. (2012) Logistics and Supply Chain Management in the Hotel Industry: Impact on Hotel Performance in Service Delivery.

[26] Prajogo, D. (2009) The Effect of Supply Chain Information Integration and Logistics Integration on Firm Performance. 1-17.

[27] Randall, W.S., Gibson, B.J., Defee, C.C., Williams, B.D. and Randall, W.S. (2013) Retail Supply Chain Management: Key Priorities and Practices. International Journal of Logistics Management, 22, 390-402.

[28] Randheer, K.A., Al-Motawa, A. and Prince, V.J. (2011) Measuring Commuters' Perception on Service Quality Using SERVQUAL in Public Transportation. International Journal of Marketing Studies, 3, 21-34. https://doi.org/10.5539/ijms.v3n1p21

[29] Salam, A., Panahifar, F. and Byrne, P.J. (2016) Retail Supply Chain Service Levels: The Role of Inventory Storage. Journal of Enterprise Information Management, 29, 887-902. https://doi.org/10.1108/JEIM-01-2015-0008

[30] Zhang, Z.-J. (2008) Literature Review of Purchasing Management IN Service Industry. Management Science and Engineering, 2, 49-53.

[31] Shang, K. and Marlow, P.B. (2007) The Effects of Logistics Competency on Perfor- 
mance. Journal of International Logistics and Trade, 5, 45-66.

https://doi.org/10.24006/jilt.2007.5.2.003

[32] Shore, B. and Venkatachalam, A.R. (2006) Evaluating the Information Sharing Capabilities of Supply Chain Partners: A Fuzzy Logic Model. International Journal of Physical Distribution \& Logistics Management, 33, 804-824. https://doi.org/10.1108/09600030310503343

[33] Song, H. and Wang, L. (2009) The Status and Development of Logistics Cost Management: Evidence from Main Land China. Benchmarking. An International Journal, 16, 657-670. https://doi.org/10.1108/14635770910987869

[34] Thogori, M. and Gathenya, J. (2014) Role of Inventory Management on Customer Satisfaction among the Manufacturing Firms in Kenya: Case Study of Delmonte Kenya. European Journal of Business and Management, 6, 209-217.

[35] Urban, T.L. (2002) The Interdependence of Inventory Management and Retail Shelf Management. International Journal of Physical Distribution and Logistics Management, 32, 41-58. https://doi.org/10.1108/09600030210415298

[36] Waller, M.A., Nachtmann, H. and Hunter, J. (2006) Measuring the Impact of Inaccurate Inventory Information on a Retail Outlet. The International Journal of Logistics Management, 17, 355-376. https://doi.org/10.1108/09574090610717527

[37] Wangari, K.L. (2015) Influence of Inventory Management Practices on Organizational Competitiveness: A Case of Safaricom Kenya Ltd. International Academic Journal of Procurement and Supply Chain Management, 1, 72-98.

[38] Meixell, M. and Patrice Luoma, P. (2015) Stakeholder Pressure in Sustainable Supply Chain Management. International Journal of Physical Distribution \& Logistics Management, 45, 69-89. https://doi.org/10.1108/IJPDLM-05-2013-0155

[39] Wu, Y., Goh, M., Yuan, C. and Huang, S. (2017) Logistics Management Research Collaboration in Asia. International Journal of Logistics Management, 28, 206-223. https://doi.org/10.1108/IJLM-09-2013-0104

[40] Tavakol, M. and Dennick, R. (2011) Making Sense of Chronbach's Alpha. International Journal of Medical Education, 2, 53-55. https://doi.org/10.5116/ijme.4dfb.8dfd

[41] Samli, A.C., et al. (2005) Developments in Retail Logistics. Journal of Marketing Channels, 13, 81-98.

https://www.researchgate.net/publication/233120180_Developments_in_Retail_Log istics

[42] Menntzer, J.T., et al. (2001) What Is Supply Chain Management. Supply Chain Management.

https://www.researchgate.net/publication/313060222_What_is_supply_chain_mana gement 